\title{
Response summation with discriminative stimuli controlling responding on separate manipulanda
}

\author{
DONALD MELTZER, BRUCE R. NIEBUHR, and ROBERT J. HAMM \\ Southern Illinois University, Carbondale, Illinois 62901
}

\begin{abstract}
Rats were reinforced on a VI 30-sec schedule for responding on one lever during light and on the other lever during tone. Responses were never reinforced when neither light nor tone was on, and a response on either lever could produce reinforcement when both stimuli were present. Although reinforcement frequency was the same during light, tone, and light plus tone, subjects made more total responses during the last condition and shifted rapidly from bar to bar only when both light and tone were present. Response summation was interpreted as an example of concurrent schedules.
\end{abstract}

Weiss (1978) has reviewed a number of studies reporting additive response summation in the free operant situation. In these studies, rats have been reinforced for pressing a lever when either of two different discriminative stimuli was present, and responses were extinguished when neither stimulus was present. The simultaneous presentation of both discriminative stimuli caused the subject to respond at higher rates than when either stimulus was presented alone. This is the phenomenon known as additive response summation. Except for one experiment by Miller (1973), these procedures have involved the use of only a single lever, but one could also predict additive summation in a different situation. If the subject were reinforced for pressing Lever A (e.g., the left-hand lever in the chamber) when one stimulus was on and was reinforced for pressing Lever B (e.g., the right-hand lever) when a second stimulus was on, the simultaneous presentation of both stimuli for a fixed period of time should cause the subject to alternate responding on both levers. The test of summation would be whether the total of Lever A response rates and Lever B response rates was greater when both stimuli were present than when only one stimulus was present. Responses on both levers would be appropriate in comparing rate during light plus tone to rate during either light or tone alone in order to make the results comparable to those that have been reported in single-lever studies. This would be true because all responses during light are compared to all responses during light plus tone in a single-lever experiment, just as all responses during tone are compared to all responses during light plus tone.

Requests for reprints should be sent to Donald Meltzer, Department of Psychology, Southern Illinois University, Carbondale, Illinois 62901. Bruce R. Neibuhg is now at the University of Texas Medical Branch, Galveston, Texas 77550. Robert J. Hamm is now at Virginia Commonwealth University, Richmond, Virginia 23220.

\section{METHOD}

\section{Subjects}

Eight male Long-Evans rats, approximately 90 days old, were used as subjects in this experiment. The rats were on a 23-h water-deprivation schedule and were given free access to water for $15 \mathrm{~min}$ in their home cages following each experimental session. Food was always available in the subjects' home cages.

\section{Apparatus}

The experimental chamber was manufactured by LVE (Model 1316) and was equipped with two bars, located approximately $2.8 \mathrm{~cm}$ above the floor; one was $3.8 \mathrm{~cm}$ from the left wall, the other was $3.8 \mathrm{~cm}$ from the right wall. There was a small pilot light approximately $2.5 \mathrm{~cm}$ above the bar. A .03-cc dipper was mounted at the base of the front wall, midway between the two bars. The chamber was completely dark when the pilot lights were off. When both lights were on, the illumination was $9.04 \mathrm{~mL}$ when measured with the light meter facing the front wall at a distance of $5.0 \mathrm{~cm}$ behind either bar. The ambient noise level produced by the blower was $63 \mathrm{~dB}$, and the auditory stimulus used in the experiment was a $714-\mathrm{Hz}$ tone that increased the noise level by $4 \mathrm{~dB}$.

\section{Procedure}

Only one lever was available to a subject during the first four sessions of the experiment. In the first session, the left lever was available to the subject, the light was on, and the tone was off. Every leverpress was reinforced. The second session differed from the first in that the left lever was withdrawn and the right lever was available to the subject. The light was off during the third and fourth sessions, but the tone was on. Only the left lever was available during the third session and only the right lever during the fourth session. Once again, each leverpress was reinforced.

Beginning with the fifth session, both levers were available to the subject throughout the session. When neither the tone nor the light was on, no response on either lever was reinforced. This condition lasted for a minimum of $30 \mathrm{sec}$, and a response on either lever delayed the end of this segment of the schedule an additional $30 \mathrm{sec}$. When the light was on, responses on Lever A were reinforced on a variable-interval (VI) 30-sec schedule, while responses on Lever B were extinguished. Lever A was the left lever for Subjects $1-4$ and the right lever for Subjects 5-8. When the tone was on, responses on Lever B were reinforced on a VI 30-sec schedule and responses on Lever A 
Table 1

Mean Response Rates Over the 21 Sessions of Summation Testing

\begin{tabular}{|c|c|c|c|c|c|c|c|c|c|c|c|}
\hline \multirow[b]{2}{*}{ Subject } & \multicolumn{4}{|c|}{ Lever A } & \multicolumn{4}{|c|}{ Lever B } & \multicolumn{3}{|c|}{ Combined } \\
\hline & Light & Tone & $\begin{array}{l}\text { No Light } \\
\text { plus } \\
\text { No Tone }\end{array}$ & $\begin{array}{l}\text { Light } \\
\text { plus } \\
\text { Tone }\end{array}$ & Light & Tone & $\begin{array}{l}\text { No Light } \\
\text { plus } \\
\text { No Tone }\end{array}$ & $\begin{array}{l}\text { Light } \\
\text { plus } \\
\text { Tone }\end{array}$ & Light & Tone & $\begin{array}{c}\text { Light } \\
\text { plus } \\
\text { Tone }\end{array}$ \\
\hline \multicolumn{12}{|c|}{ Lever A Left, Lever B Right } \\
\hline $\begin{array}{l}1 \\
2 \\
3 \\
4\end{array}$ & $\begin{array}{r}12.1 \\
8.9 \\
11.6 \\
10.6\end{array}$ & $\begin{array}{r}1.8 \\
.6 \\
.8 \\
1.0\end{array}$ & $\begin{array}{l}2.2 \\
1.1 \\
1.7 \\
1.5\end{array}$ & $\begin{array}{l}9.6 \\
9.7 \\
3.6 \\
8.2\end{array}$ & $\begin{array}{l}5.7 \\
1.8 \\
5.0 \\
3.4\end{array}$ & $\begin{array}{r}15.4 \\
8.7 \\
28.8 \\
9.0\end{array}$ & $\begin{array}{l}5.4 \\
1.9 \\
8.9 \\
4.2\end{array}$ & $\begin{array}{r}13.4 \\
6.2 \\
32.3 \\
8.0\end{array}$ & $\begin{array}{l}17.8 \\
10.7 \\
16.6 \\
14.0\end{array}$ & $\begin{array}{r}17.2 \\
9.3 \\
29.6 \\
10.0\end{array}$ & $\begin{array}{l}23.0 \\
15.9 \\
35.9 \\
16.2\end{array}$ \\
\hline \multicolumn{12}{|c|}{ Lever A Right, Lever B Left } \\
\hline $\begin{array}{l}5 \\
6 \\
7 \\
8\end{array}$ & $\begin{array}{l}18.7 \\
20.8 \\
15.6 \\
10.7\end{array}$ & $\begin{array}{r}7.1 \\
14.1 \\
.9 \\
.6\end{array}$ & $\begin{array}{l}6.9 \\
8.0 \\
2.2 \\
1.5\end{array}$ & $\begin{array}{l}24.1 \\
21.4 \\
16.4 \\
11.0\end{array}$ & $\begin{array}{r}4.4 \\
2.8 \\
.7 \\
.9\end{array}$ & $\begin{array}{r}7.2 \\
14.6 \\
7.8 \\
9.1\end{array}$ & $\begin{array}{l}3.6 \\
3.3 \\
1.9 \\
2.7\end{array}$ & $\begin{array}{r}10.1 \\
12.4 \\
4.6 \\
6.9\end{array}$ & $\begin{array}{l}23.1 \\
23.6 \\
16.3 \\
11.6\end{array}$ & $\begin{array}{r}14.3 \\
28.7 \\
8.7 \\
9.7\end{array}$ & $\begin{array}{l}34.2 \\
33.8 \\
21.0 \\
17.9\end{array}$ \\
\hline
\end{tabular}

Note-Included are response rates in each stimulus condition for both Levers $A$ and $B$. Also included are the combined response rates of both levers in light, tone, and the compound stimulus, light plus tone. Reinforcement on a VI 30-sec schedule was available in Lever $A$ in light and in light plus tone. Reinforcement was available on Lever $B$ in tone and in light plus tone. Reinforcement was not available for pressing either lever in no light plus no tone.

were extinguished. Tone and light presentations each lasted until the subject had received four reinforcements; each stimulus was present three times in a session. The stimulus sequence was changed every 3 rd day. This procedure was continued for a total of 30 sessions.

The response contingencies during light, tone, and no light plus no tone remained the same for the following 21 sessions. However, another stimulus condition was also included. On some occasions light and tone were presented simultaneously. The schedule was still VI $30 \mathrm{sec}$ during the light plus tone presentation, but instead of reinforcing the subject for responding on only one of the levers, a response on either lever could produce a reinforcement. Thus, the frequency of reinforcement was the same when light, tone, or light plus tone was present. The only difference was that when either light or tone was present, the subject had to discriminate between the left and right levers in order to make the correct response. When light plus tone was present, no discrimination was necessary. There was always a no-light plus no-tone interval lasting a minimum of $30 \mathrm{sec}$ between each of the different discriminative stimuli (i.e., light, tone, or light plus tone), and each of the discriminative stimuli was presented twice during a session and lasted until the subject had received four reinforcements.

\section{RESULTS AND DISCUSSION}

The results as summarized in Table 1 clearly show that the subjects learned all of the discriminations necessary for accurate performance. Response rate on Lever $A$ was higher during light than was rate on Lever B. Response rate on Lever B was higher during tone than during no light plus no tone; rate on Lever $B$ was also higher during tone than was rate on Lever A. Similarly, response rates on both Lever A and Lever B were higher in light plus tone than in no light plus no tone. In short, when the stimulus conditions indicated that reinforcement would be available for responding on one of the levers, response rate on that lever was higher than when stimulus conditions indicated that reinforcement was not available. An analysis indicated that no stimulus dominance effect occurred; that is, overall, response rates on Lever A and Lever B did not differ.

The key question was whether total response rate, the combined rate of responding on both levers, would be greater during light plus tone than during either light or tone alone. Table 1 shows that total response rate was greater in light plus tone than in light or tone alone for each subject. This effect was statistically reliable; the overall $\mathrm{F}$ was significant $[\mathrm{F}(2,14)=12.00$, $\mathrm{p}<.01]$, and Tukey HSD comparisons indicate that response rate in light plus tone was greater than rate in light or tone $(p<.01)$ and that response rate in light and tone did not differ. Therefore, we may conclude that the subjects showed additive response summation.

Event recordings were also made of each subject for two sessions of summation testing in order to observe the patterning of response. During light plus tone presentations, the typical pattern of responding found was an alternation between levers with short bursts of responding on each lever. Only Subject 3 failed to distribute responses in this manner; as Table 1 shows, Subject 3 made very few responses on Lever A.

It appears, then, that in the presence of the compound stimulus light plus tone, a rat responds in the appropriate manner for light (pressing Lever A) and in the appropriate manner for tone (pressing Lever B), but control shifts between light and tone. The net effect of this was additive response summation. These results also suggest that summation occurs primarily because of a shift, or oscillation, in stimulus control. As one element loses control, the other gains control. Response summation thus may be seen to have similarities to the effects of concurrent schedules.

\section{REFERENCES}

Mille r, L. Compounding of discriminative stimuli that maintain responding on separate response levers. Journal of the Experimental Analysis of Behavior, 1973, 20, 57-69.

WEISS, S. J. Discriminated response and incentive processes in operant conditioning: A two factor model of stimulus control. Journal of the Experimental Analysis of Behavior, 1978, 30, 361-381.

(Received for publication April 19, 1979.) 